\title{
PENGARUH INPUT TERHADAP PRODUKSI USAHATANI LADA PUTIH (Muntok White Pepper) DI DESA KUNDI KECAMATAN SIMPANG TERITIP KABUPATEN BANGKA BARAT
}

\author{
Yudi Sapta Pranoto \\ Staf Pengajar Program Studi Agribisnis, Fakultas Pertanian, Perikanan dan Biologi, \\ Universitas Bangka Belitung \\ Email : udhei_sapta@yahoo.com
}

\begin{abstract}
The development of white pepper in Bangka Belitung Province is an interesting issue to be concerned, because of it has been well-known worldwide as Muntok White Pepper. This research based on the relationship among input, process, and output produced also high operating cost of white pepper farming. The focus of this research are (1) Calculating the amount of production cost, income, and the lowest output farmers' price in Kundi Village, (2) Analyzing production inputs which allegedly influencing the amount of white pepper production in Kundi Village. The method used in this research was survey method and desk study and field study approach also data analyzing used Break Even Point and regression analysis used production function of Cobb Douglas, therefore the result of this research was (1) The amount of cost spent by the farmers in the first harvest season is Rp. 77.080.861, the income of white pepper farming in the first harvest season is Rp. 99.556.639. while BEP of price of white pepper is Rp.67.615 and BEP of Production of white pepper is Rp. 493 kilograms. (2) There are two variables influencing the amount of production of white pepper farming in Kundi Village, that is fertilizer $\left(X_{1}\right)$ and labor $\left(X_{2}\right)$.
\end{abstract}

Key Words : Muntok White Pepper, Break Event Point, Regression Analysis

\section{PENDAHULUAN}

Lada putih dari Provinsi Bangka Belitung mempunyai Brand Image dan telah dikenal di dunia dengan sebutan Muntok White Pepper. Pada tahun 2009, nilai ekspor lada putih provinsi Bangka Belitung sebesar US \$ 26228153.71 (BPS Provinsi Bangka Belitung, 2010) atau sekitar 40 persen dari total produksinya.

Namun kondisi sekarang volume ekspor lada putih Bangka Belitung mengalami tren penurunan. Berdasarkan data Asosiasi Exportir Lada Indonesia (AELI) Bangka Belitung Tahun 2014, menunjukan realisasi eskpor lada putih Bangka Belitung pada tahun 2011 sebesar 6.735 ton dengan nilai US \$ 55.246,30 kemudian tahun 2012 mengalami kenaikan volume eskpor sebesar 7.291,4 ton dengan nilai US \$ 68.272,70 dan tahun 2013 mengalami penurunan sebesar 31 persen atau sebesar 5.527,5 dengan nilai US \$ $80.847,66$.
Kabupaten Bangka Barat merupakan sentra poduksi lada putih nomor tiga setelah Kabupaten Bangka Selatan dan Kabupaten Belitung. Berdasarkan data dari Dinas Pertanian, Perkebunan dan Peternakan Kabupaten Bangka Barat Tahun 2014, selama 3 tahun terakhir yaitu periode 2011 sampai dengan 2013 mengalami penurunan pertumbuhan produksi sebesar 139 persen. Penurunan produksi ini disebabkan adanya berbagai permasalahan yang dihadapi petani yaitu mahalnya harga sarana produksi dan ketersediaannya terbatas, serangan hama dan penyakit dan semakin menurunya luas areal penanaman.

Kecamatan Simpang teritip merupakan sentra produksi lada putih di Kabupaten Bangka Barat. Besarnya produksi lada putih di Kecamatan Simpang Teritip salah satunya disumbang oleh Desa Kundi. Produksi lada putih yang berasal dari Desa Kundi akan mempengaruhi total produksi lada putih di Kabupaten Bangka Barat. 
Keterkaitan antara input, proses, dan output yang dihasilkan akan mempengaruhi keberlangsungan kegiatan usahatani lada putih, biaya investasi dan biaya operasional terutama biaya tenaga kerja dan biaya pupuk cukup tinggi. Oleh karena itu, untuk meningkatkan produksi lada putih harus didukung dengan penambahan input.

Berdasarkan uraian di atas, ada sejumlah pertanyaan menarik yang perlu segera diketahui jawabannya yaitu: berapa besar biaya produksi dan pendapatan yang diterima petani lada putih di Desa Kundi, seiring dengan meningkatnya biaya faktor produksi input apakah masih bisa memberikan pendapatan yang layak dan berapa batas terendah harga yang layak, agar usahatani lada putih masih terus dipertahanakan. Lalu, faktor-faktor produksi apa saja yang berpengaruh terhadap produksi lada putih di Desa Kundi. Pertanyaan ini penting untuk segera dijawab, sehingga perlu upaya-upaya mengembalikan kejayaan lada putih untuk menyusun langkah-langkah strategis dalam menentukan kebijakan usahatani lada putih di Provinsi Bangka Belitung. Penelitian ini bertujuan untuk : 1) menghitung besarnya biaya produksi, pendapatan dan harga output terendah petani lada putih, 2) menganalisis input-input produksi yang berpengaruh terhadap produksi lada putih

\section{METODE PENELITIAN}

Penelitian ini akan dilakukan di Desa Kundi Kecamatan Simpang Teritip Propinsi Bangka Belitung. Pemilihan Desa Kundi dilakukan secara sangaja (Purposive) didasarkan pertimbangan bahwa Desa Kundi merupakan sentra produksi lada putih khususnya di Kecamatan Simpang Teritip dan kegiatan usahatani lada putih sudah dilakukan secara turun temurun oleh masyarakat. Penelitian ini akan dilaksanakan selama 5 bulan, yakni dari bulan Februari sampai dengan Juli 2016.

Penelitian ini dilakukan dengan menggunakan metode survey. dalam penelitian ini adalah data primer dan data sekunder baik secara kualitatif maupun kuantitatif, yang terdiri dari data usahatani lada putih, meliputi produksi, dan input fisik usahatani, harga input dan output.

Penelitian ini dilakukan dengan dua pendekatan, yaitu desk study dan field study. Desk study ditujukan pada penelaahan berbagai hasil-hasil penelitian maupun kajian yang telah ada tentang agribisnis lada putih, serta berbagai bentuk kebijakan pemerintah yang terkait. Field study akan menggunakan pendekatan teknik wawancara dan FGD yang dibantu dengan pengumpulan data primer dari stakeholders agribisnis lada putih. Untuk lebih jelasnya pendekatan penelitian dapat dilihat pada Gambar 1 berikut ini.

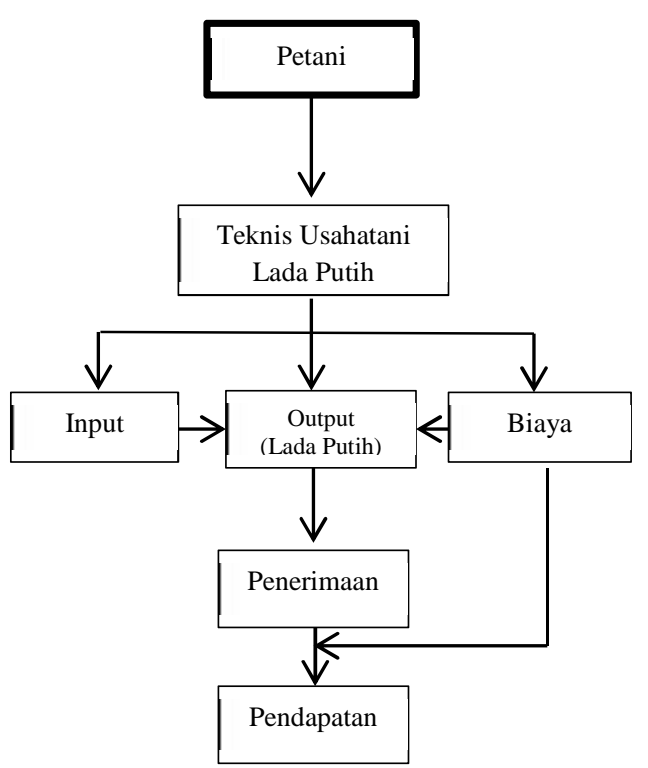

Gambar 1. Pendekatan Penelitian

Data yang diperoleh dari usahatani lada putih, diolah secara tabulasi dan dianalisis secara kualitatif dan kuantitatif. Menjawab tujuan pertama mengenai besarnya biaya dan pendapatan usahatani lada putih menggunakan rumus matematik dan metode Break Even Point (BEP), secara umum sebagai berikut (Rahim dan Hastuti, 2007).

$$
\begin{array}{rrrl}
\mathrm{Pd} & =\mathrm{TR}-\mathrm{TC} & B E P \text { Rupiah } & =\frac{F C}{1-\frac{V C}{T R}} \\
\mathrm{TR} & =\mathrm{Y} . \mathrm{Py} \\
\mathrm{TC} & =\mathrm{FC}+\mathrm{VC} & \text { BEP Unit } & =\frac{F C}{P-V C}
\end{array}
$$

Dimana :

$\mathrm{Pd}=$ Pendapatan usahatani

$\mathrm{TR}=$ Total penerimaan (total revenue)

$\mathrm{TC}=$ Total biaya (total cost) 
$\mathrm{FC}=$ Biaya tetap (fixed cost)

$\mathrm{VC}=$ Biaya variabel (variable cost)

$\mathrm{Y}=$ Produksi diperoleh dalam usahatani

Py = Harga $Y$

Untuk menjawab tujuan kedua yaitu

menganalisis faktor-faktor input yang berpengaruh terhadap produksi lada putih digunakan analisis regresi berganda dengan menggunakan fungsi produksi Cobb Douglas, sehingga dalam penelitian ini diperoleh persamaan sebagai berikut :

$\mathrm{Y}=\mathrm{a} \cdot \mathrm{X}^{1 \beta 1} \mathrm{X}^{2 \beta 2} \mathrm{X}^{3 \beta 3} \mathrm{X}^{4 \beta 4}$ eл...Pers (1)

$\operatorname{Ln} Y=\operatorname{In} \alpha+\beta_{1} \operatorname{Ln} X_{1}+\beta_{2} \operatorname{Ln} X_{2} \beta_{3} \operatorname{Ln}$ $X_{3}+\beta_{4} \operatorname{Ln} X_{4}+$ e...........Pers (2)

Dimana :

$\mathrm{Y}=$ Produksi tanaman lada putih $(\mathrm{Kg} / \mathrm{Ha})$

$\alpha=$ Konstanta

$\mathrm{X}_{1}=$ Luas lahan

$\mathrm{X}_{2}=$ Pupuk

$\mathrm{X}_{3}=$ Tenaga kerja

$\mathrm{X}_{4}=$ Pestisida

$\beta_{1-} \beta_{4}=$ Koefisien arah regresi masingmasing variabel bebas $\mathrm{X}_{1} \ldots \ldots \mathrm{X}_{6}$

$\mathrm{e} \quad=$ Gangguan stokhatis atau kesalahan
HASIL DAN PEMBAHASAN

Biaya dan Pendapatan Usahatani Lada

Putih

\section{Biaya Produksi}

Biaya produksi yang dibahas dalam penelitian ini adalah semua biaya yang dikeluarkan oleh responden dalam proses produksinya saat melakukan usahatani. Adapun biaya yang dikeluarkan oleh responden lada putih di Desa Kundi sampai periode panen pertama berupa biaya tetap dan biaya variabel. Biaya tetap merupakan biaya dimana besar kecilnya tergantung pada besar kecilnya produksi sedangkan biaya variabel merupakan biaya habis pakai untuk satu kali produksi.

\section{Biaya Tetap}

Dalam hal ini yang termasuk dalam biaya tetap dalam usahatani lada putih adalah biaya penyusutan peralatan yang digunakan. Adapun biaya rata-rata pengadaan peralatan yang dikeluarkan oleh responden lada putih sampai periode panen pertama tersebut dapat dilihat pada Tabel 1.

Tabel 1. Biaya tetap rata-rata alat pertanian di Desa Kundi, 2016.

\begin{tabular}{clccc}
\hline No & Jenis & $\begin{array}{c}\text { Keperluan } \\
\text { Rata-Rata (Buah) }\end{array}$ & $\begin{array}{c}\text { Harga Satuan } \\
(\mathrm{Rp})\end{array}$ & $\begin{array}{c}\text { Jumlah Harga } \\
\text { rata-rata (Rp) }\end{array}$ \\
\hline 1. & Tangki Semprot & 1 & 328.917 & 328.917 \\
2. & Parang & 2 & 48.250 & 96.500 \\
3. & Kedik & 2 & 30.000 & 60.000 \\
4. & Cangkul & 2 & 50.583 & 101.167 \\
5. & Suyak & 3 & 24.611 & 73.833 \\
6. & Linggis & 2 & 22.123 & 44.250 \\
7. & Ember & 6 & 21.389 & 128.333 \\
\hline \multicolumn{2}{r}{ Jumlah } & & & 833.000 \\
\hline
\end{tabular}

Sumber : Olahan Data Primer, 2016

Tabel 2.Biaya tetap rata-rata penyusutan alat di Desa Kundi, 2016

\begin{tabular}{|c|c|c|c|c|}
\hline No & Jenis & $\begin{array}{l}\text { Umur ekonomis } \\
\text { (Th) }\end{array}$ & $\begin{array}{l}\text { Jumlah Harga } \\
\text { rata-rata (Rp) }\end{array}$ & $\begin{array}{l}\text { Nilai Penyusutan rata- } \\
\text { rata }(\mathrm{Rp})\end{array}$ \\
\hline 1. & Tangki Semprot & 3 & 328.917 & 113.528 \\
\hline 2. & Parang & 2 & 96.500 & 48.250 \\
\hline 3. & Kedik & 2 & 60.000 & 30.000 \\
\hline 4. & Cangkul & 3 & 101.167 & 33.722 \\
\hline 5. & Suyak & 3 & 73.833 & 24.611 \\
\hline 6. & Linggis & 3 & 44.250 & 14.750 \\
\hline 7. & Ember & 1 & 128.333 & 128.333 \\
\hline \multicolumn{3}{|c|}{ Jumlah } & 833.000 & 393.194 \\
\hline
\end{tabular}

Sumber : Olahan Data Primer, 2016 
Menurut Suratiyah (2008) penyusutan peralatan dihitung menggunakan metode garis lurus yaitu harga beli dikurangi nilai sisa (nilai akhir) dibagi umur ekonomis alat yang dipakai. Dalam perhitungan ini, nilai susut dianggap konstan setiap tahunnya, nilai sisa dianggap nol diasumsikan alat tersebut tidak laku apabila dijual kembali. Untuk lebih jelas, bisa dilihat pada Tabel 2 .

\section{Biaya Variabel}

Pada penelitian ini biaya variabel adalah biaya yang habis dipakai sampai periode panen pertama, biaya variabel seperti: biaya pembelian bibit, pupuk, herbisida, dan upah tenaga kerja. Biaya variabel rata-rata yang dikeluarkan oleh

Tabel 3. Biaya variabel rata-rata per hektar sampai periode panen pertama di Desa Kundi, 2016.

\begin{tabular}{rlrcrr}
\hline No & Jenis & $\begin{array}{c}\text { Keperluan } \\
\text { Rata-rata }\end{array}$ & Satuan & $\begin{array}{c}\text { Harga } \\
\text { Satuan (Rp) }\end{array}$ & $\begin{array}{c}\text { Biaya Variabel } \\
\text { (Rp) }\end{array}$ \\
\hline 1. & Bibit & 2.332 & Pohon & 7.610 & 17.747 .500 \\
2. & Pupuk & 1.652 & $\mathrm{Kg}$ & 3.202 & 5.289 .467 \\
3. & Pestisida & 29 & Liter & 37.644 & 1.087 .283 \\
4. & a. Tajar kecil & 2.332 & Buah & 3.000 & 6.995 .000 \\
& b. Tajar besar & 2.332 & Buah & 17.000 & 39.638 .333 \\
5. & Upah tenaga kerja & 65 & HOK & 91.232 & 5.930 .083 \\
\hline \multicolumn{2}{r}{ Jumlah } & & & & 76.687 .167 \\
\hline
\end{tabular}

Sumber : Olahan Data Primer, 2016

Tabel 4. Biaya total produksi rata-rata per hektar sampai perode panen pertama di Desa Kundi, 2016.

\begin{tabular}{llrc}
\hline No & Biaya Produksi & Jumlah (Rp) & Persentase (\%) \\
\hline 1. & Biaya Tetap & & \\
& - Biaya penyusutan peralatan & 393.194 & 0,5 \\
2. & Biaya Variabel & & \\
& - Bibit (pohon) & 17.747 .500 & 23 \\
- Pupuk (kg) & 5.289 .467 & 6,9 \\
- Herbisida (liter) & 1.087 .283 & 1,4 \\
- Tajar kecil (buah) & 6.995 .000 & 9,1 \\
- Tajar besar (buah) & 39.638 .333 & 51,4 \\
- Upah tenaga kerja (HOK) & 5.930 .083 & 7,7 \\
\hline Jumlah & 77.080 .861 & 100
\end{tabular}

Sumber : Olahan Data Primer, 2016 


\section{Penerimaan dan Keuntungan}

Penerimaan merupakan hasil kali jumlah produksi dengan harga jual persatuan produk. Harga jual merupakan harga dasar untuk satu kilogram lada putih. Penerimaan dalam hal ini merupakan penerimaan ratarata yang diperoleh responden lada putih di Desa Kundi sampai periode panen pertama yang dapat dilihat pada Tabel 5 .

Tabel 5. Penerimaan rata-rata per hektar sampai periode panen pertama di Desa Kundi ,2016

\begin{tabular}{llc}
\hline No & Uraian & Jumlah \\
\hline 1. & Total Produksi (Y) & $1.140 \mathrm{Kg}$ \\
2. & Harga Jual (Py) & Rp.156.217/Kg \\
3. Penerimaan (Y.Py) & Rp. 176.637.500 \\
\hline \multicolumn{2}{l}{ Sumber: Olahan Data Primer, 2016 }
\end{tabular}

Pendapatan dalam hal ini merupakan keuntungan rata-rata yang di peroleh responden sampai periode panen pertama, lebih jelasnya dapat dilihat pada Tabel 6 .

Tabel 6. Pendapatan rata-rata per hektar sampai periode panen pertama di Desa Kundi,2016

\begin{tabular}{clr}
\hline No & Uraian & Jumlah $(\mathrm{Rp})$ \\
\hline 1. & Penerimaan & 176.637 .500 \\
2. & Biaya Produksi & 77.080 .861 \\
3. & Pendapatan & 99.556 .639 \\
\hline
\end{tabular}

Sumber: Olahan Data Primer, 2016

Dalam penelitian ini, Break Even Point (BEP) harga akan tercapai pada saat harga lada putih sebesar Rp. 67.615 dan harga jual lada putih dijual pada saat harga rata-rata sebesar $\mathrm{Rp}$ 156.217. Nilai $\mathrm{Rp}$. 67.615 artinya adalah titik balik modal dalam usahatani lada putih ini yaitu pada saat harga lada putih sebesar Rp. 67.615.

Sedangkan Break Even Point (BEP) produksi akan tercapai pada saat produksi lada putih sebesar $493 \mathrm{~kg}$ per hektar dan rata-rata produksi lada pada saat ini sebesar $1.140 \mathrm{~kg}$. Angka $493 \mathrm{~kg}$ per hektar artinya adalah titik balik modal dalam usahatani lada putih ini yaitu pada saat produksi lada putih sebesar $493 \mathrm{~kg}$ per hektar.

\section{Hasil Pendugaan Model Regresi}

Hasil pendugaan analisis regresi berganda, pengaruh produksi lada putih sebagai variabel dependen (Y), dengan faktor-input usahatani lada putih yaitu luas lahan $\left(\mathrm{X}_{1}\right)$, pupuk $\left(\mathrm{X}_{2}\right)$, tenaga kerja $\left(\mathrm{X}_{3}\right)$, serta pestisida $\left(\mathrm{X}_{4}\right)$. Dalam proses pengolahan data, awalnya memang memasukan semua input seperti luas lahan, pupuk, tenaga kerja, dan herbisida. Tetapi karena terdapatnya multikolinearitas, maka input luas lahan dicoba dikeluarkan dari proses pengolahan data demi untuk mendapatkan model yang sekiranya lebih baik dari yang sebelumnya, hal ini diasumsikan bahwa input luas lahan mempunyai pengaruh yang positif penyebab terjadinya multikolinearitas tersebut. Fungsi produksi bertipe Coob-Douglas yang di transformasikan ke dalam bentuk double logaritma natural (ln). Berdasarkan persaman dan nilai-nilai yang ada, maka didapat nilai persamaan fungsi produksi bertipe Coob-Douglas adalah sebagai berikut :

$\mathrm{Y}=$ anti $\mathrm{Ln}-156,203 \mathrm{X}_{1}^{0.625} \mathrm{X}_{2}^{2,119} \mathrm{X}_{3}^{4,376}$

Persamaan liniernya adalah sebagai berikut :

$$
\begin{aligned}
\operatorname{Ln} Y= & \operatorname{Ln}-156,203+0,625 \operatorname{Ln} X_{1}+2,119 \\
& \operatorname{Ln~} X_{2}+4,376 \operatorname{Ln} X_{3} \\
& \text { Persamaan model di atas didapatkan }
\end{aligned}
$$
dari nilai-nilai yang ada pada Tabel 7. Untuk melihat nilai-nilai hasil pendugaan model regresi tersebut dapat dilihat pada Tabel 7.

\begin{tabular}{|c|c|c|c|c|c|}
\hline No & $\begin{array}{l}\text { Variabel } \\
\text { Bebas }\end{array}$ & $\begin{array}{l}\text { Koef. } \\
\text { Regresi }\end{array}$ & T hitung & $\begin{array}{l}p \text {-value } \\
\text { (sig) }\end{array}$ & Ket \\
\hline & Intercept & $-156,203$ & & & \\
\hline 1 & Pupuk $\left(\mathrm{X}_{1}\right)$ & 0,625 & 26,908 & 0,000 & $* *$ \\
\hline 2 & $\begin{array}{l}\text { Tenaga } \\
\text { kerja }\left(X_{2}\right)\end{array}$ & 2,119 & 2,903 & 0,005 & $* *$ \\
\hline 3 & $\begin{array}{l}\text { Pestisida } \\
\left(\mathrm{X}_{3}\right)\end{array}$ & 4,376 & 1,387 & 0,171 & $*$ \\
\hline & $\begin{array}{l}\mathrm{F} \text { hitung } \\
\mathrm{R}^{2}\end{array}$ & $\begin{array}{c}556,572 \\
96,6 \%\end{array}$ & & 0,000 & \\
\hline
\end{tabular}

Tabel 7. Hasil Pendugaan Model Regresi Berganda

Sumber : Olahan Data Primer, 2016 


\section{Pengaruh Input Terhadap Produksi Lada Putih}

\section{Uji Statistik Koefisien Determinasi $\left(\mathbf{R}^{2}\right)$}

Dari hasil pendugaan model regresi pada Tabel 7 diperoleh bahwa, nilai koefisien determinasi $\left(\mathrm{R}^{2}\right)$ adalah sebesar 96,6 persen, hal ini berarti bahwa sebesar 96,6 persen produksi tanaman lada putih di Desa Kundi dipengaruhi oleh variabel bebas seperti pupuk $\left(\mathrm{X}_{1}\right)$ yang terdiri dari (pupuk urea, pupuk phonska, pupuk SP-36 pupuk mutiara dan organik), tenaga kerja $\left(\mathrm{X}_{2}\right)$, dan pestisida $\left(\mathrm{X}_{3}\right)$, sementara sisanya sebesar 0,4 persen produksi lada putih dipengaruhi oleh variabel atau input yang lain yang tidak diteliti dalam penelitian ini.

\section{Uji F}

Berdasarkan nilai signifikansi pada Tabel 7, yang mempunyai nilai signifikansi sebesar 0,000 atau sebesar 0 persen, maka dapat dijelaskan secara bersama-sama input pupuk, tenaga kerja, dan herbisida berpengaruh positif atau berpengaruh nyata terhadap produksi lada putih pada taraf kepercayaan 95 persen atau taraf toleransi 0,05 atau 5 persen.

\section{Uji T}

Berdasarkan Tabel 7, terlihat bahwa hasil nilai signifikansi dari input pupuk $\left(\mathrm{X}_{1}\right)$ adalah sebesar 0,000 persen atau sebesar 0 persen, maka hal ini menunjukkan bahwa input pupuk berpengaruh nyata terhadap produksi lada putih pada tingkat kepercayaan 95 persen, kemudian nilai signifikansi dari input tenaga kerja $\left(\mathrm{X}_{2}\right)$ adalah sebesar 0,005 persen atau sebesar 0,5 persen, maka hal ini menunjukkan bahwa input tenaga kerja berpengaruh nyata pada tingkat kepercayaan 95 persen terhadap produksi tanaman lada putih, sedangkan input pestisida $\left(\mathrm{X}_{3}\right)$ yang mempunyai nilai signifikansi sebesar 0,171 persen atau sebesar 17,1 persen, maka hal ini menunjukkan bahwa input pestisida tidak berpengaruh nyata terhadap produksi tanaman lada putih.

Dapat juga dijelaskan bahwa :

- Input pupuk

Berdasarkan hasil regresi diketahui bahwa variabel pupuk mempunyai hubungan positif dan berpengaruh nyata pada produksi lada putih di Desa Kundi. Dari hasil analisis diperoleh nilai koefisien regresi untuk input pupuk $\left(\mathrm{X}_{1}\right)$ adalah sebesar 0,625 artinya penambahan input pupuk sebesar 1 persen akan menaikan nilai produksi sebesar 0,625 persen.

\section{- Input Tenaga Kerja}

Dari hasil regresi diketahui bahwa variabel tenaga kerja mempunyai hubungan positif dan berpengaruh nyata pada produksi lada putih di Desa Kundi. Nilai koefisien regresi untuk input tenaga kerja $\left(\mathrm{X}_{2}\right)$ adalah sebesar 2,119, maka penambahan input tenaga kerja sebesar 1 persen akan menaikkan produksi sebesar 2,119 persen.

\section{- Input Pestisida}

Dari hasil regresi diketahui bahwa variabel pestisida mempunyai hubungan positif dan tidak berpengaruh nyata pada produksi lada putih di Desa Kundi. Nilai koefisien regresi untuk input pestisida $\left(\mathrm{X}_{3}\right)$ adalah sebesar 4,376, maka penambahan input herbisida sebesar 1 persen akan menaikan produksi sebesar 4,376 persen.

\section{KESIMPULAN}

1. Besarnya biaya yang dikeluarkan petani dalam usahatani lada putih sampai panen pertama sebesar Rp. 77.080.861, dan pendapatan usahatani lada putih pada panen pertama sebesar Rp. 99.556.639. Sedangkan BEP harga lada putih sebesar Rp. 67.615, dan BEP produksi sebesar Rp. 493 kilogram.

2. Terdapat 2 variabel yang berpengaruh terhadap produksi usahatani lada putih di Desa Kundi yaitu pupuk dan tenaga kerja.

\section{DAFTAR PUSTAKA}

Angga S. (2013), Pengaruh dan Efisiensi Penggunaan Input Pada Usahatani Lada Putih (Muntok White Pepper) di Desa Terentang III Kecamatan Koba Kabupaten Bangka Tengah. Skripsi Mahasiswa Jurusan Agribisnis Fakultas Pertanian Perikanan dan Biologi Universitas Bangka Belitung. 
Badan Pusat Statistik Provinsi Bangka Belitung. $\quad 2010 . \quad$ Statistik Perdagangan Luar Negeri EksporImpor. Provinsi Kepulauan Bangka Belitung.

Bangun, W. 2007. Teori Ekonomi Mikro : PT Refika Aditama. Bangdung.

Bowo, T. 2010. Analisis Faktor-Faktor Yang Mempengaruhi Produksi Belimbing. Program Studi Ilmu Ekonomi dan Studi Pembangunan. [Skripsi] : Universitas Diponegoro. Semarang.

Daniel, M. 2004. Pengantar Ekonomi Pertanian : PT Bumi Aksara. Jakarta.

Dinas Pertanian, Perkebunan dan Peternakan. 2013. Statistik Perkebunan Tahun 2013. Kabupaten Bangka Barat

Erik. 2013. Optimalisai Produksi Pada Usahatani Lada Putih (Muntok White Pepper) di Desa Ranggung Kecamatan Payung Kabupaten Bangka Selatan. Skripsi Mahasiswa Jurusan Agribisnis Fakultas Pertanian Perikanan dan Biologi Universitas Bangka Belitung.

Nurasa T. 2006. Analisis Kelayakan Finansial Lada Putih di Kabupaten Bangka. Pusat Penelitian dan Pengembangan Sosial Ekonomi Pertanian. SOCA (Socio Economic Of Agriculturre And Agribusiness) Volume 3 November 2006

Mawarnita, C. 2013. Analisis Kelayakan Usaha Lada (Piper Nigrum L.) di Desa Kundi Kecamatan Simpang Teritip Kabupaten Bangka Barat.Skripsi Mahasiswi Jurusan Agribisnis Institut Pertanian Bogor. Bogor. Repository.ipb.ac.id. [diakses pada tanggal 3 Juli 2016]

Mubyarto. 1989. Pengantar Ekonomi Pertanian : LP3ES. Jakarta.
Muntoro, Pranoto Y.S. 2015. Masihkah Lada Putih Menjadi tumpuan Ekonomi masyarakat Bangka Belitung. Jurnal Ekonomika Volume IV Nomor 1. Fakultas Ekonomi. Universitas Borneo Tarakan. Kalimantan Utara.

Sabrata, E. 2006. Analisis Efisiensi Penggunaan Fktor Produksi Usahatani Lada Putih Di Desa Jangkang Kecamatan Dendang Kabupaten Belitung Timur. Program Studi Pertanian. [Skripsi] : Universitas Bangka Belitung. Bangka.

Suratiyah, K. 2011. Ilmu Usahatani : Penebar Swadaya. Jakarta.

Soekartawi. 2003. Agribisnis (Teori dan Aplikasinya) : PT Raja Grafindo Persada. Jakarta.

Rahim, A. dan Hastuti, D. 2007. Pengantar, Teori dan Kasus Ekonometrika Pertanian : Penebar Swadaya. Jakarta.

Pranoto Y.S. 2016. Faktor yang Mempengaruhi Keputusan Petani Terhadap Hasil Panen Lada Putih di Kecamatan Simpang Teritip Kabupaten Bangka Barat. Jurnal Agraris. Volume 2 Nomor 1. Program Studi Agribisnis Universitas Muhammadiyah Jogyakarta. Jogyakarta 